\title{
The relationship between rice and the housing of rice-growers in the north of Iran
}

\author{
M. Yousefnia Pasha \\ Department of Architecture, Sama Technical \& Vocational School, \\ Sari Branch, Iran
}

\begin{abstract}
The rice ecosystem has not only shaped specific culture and life but also the form of houses and the structure of villages in the north of Iran. Rice is present in all aspects of the rice-grower's lives. Villages and houses in this ecosystem have evolved which are bound to the culture and are sustainable, compatible with natural environment and also very beautiful. Indeed, in this rural context, inhabitants intimately interface with the context.

Through this article, a complete description of some aspects of a rice ecosystem in part of north of Iran will be presented, and especially tries to find out the close relationship between the environment, climate and the use of construction materials from nature including jungle and rice field, manner of construction technologies, their livelihood, and economical aspects to create the outcome.

This work will be beneficial to the villagers, architects, organizations, and all cultural, economical, foundations which are involved with rural development.
\end{abstract} Keywords: rice, architecture, rural architecture, Iran, Mazandaran.

\section{Introduction}

According to a text published by FAo, evidence of rice cultivation in Iran dates back to 100 B.C. [2]. Domestication of rice production was the main course to change Mazandaran's nomads into settlers. The complexity of the rice production process and different rice application provides a base framework to shape the culture of these people.

Rice farming starts at the beginning of spring and ends at the beginning of autumn. Therefore, Mazandaran's farmers divide the year into two seasons, 
spring and autumn. Spring and summer are working seasons, and autumn and winter are resting and evening party seasons.

It is spring, garden of tulips, I don't want to die

Summer is working season, I don't want to die

I should gather winter food during autumn

Winter is cold; I don't want to die (a part of folklore poem)

Rice production is an exhausting process. It involves cooperation of all family members and friends including women, men and children. Rice is planted diligently by hand, in person. Work is subdivided into different parts for different age groups and genders among the family by different time of a day and seasons. Children are brought up in the heart of rice culture and civilization while helping out their family. Social activities of farmers also rely on working and resting seasons of rice planting. Rice planting methods, rice derivatives, method of rice maintenance and consumption besides networks of rivers and their branches for irrigation has affected architecture and the context of farmer's villages.

The book written by Darvish Ali koulaeeyan [3] is the only research about how Mazandaran inhabitant's culture and lives were being formed when rice was just started to be cultivated in the beginning of civilization in the regions of Mazandaran and Gilan. It was illustrated through historical and linguistic standpoints. In addition, the development of rural architecture being shaped by rice culture will be addressed.

\section{Methodology}

Understanding the relationship between rice and lifestyle of rice-growers was my major aim for this study. I strongly believe vernacular and rural architecture has some useful instruction for new ones. For this study, villages in Mazandaran have been chosen since rice production was their primary industry. I have done a qualitative research choosing conscious samples of about 60 villages in 4 different regions in this province. All of the data has been collected mainly through direct observation and interview in addition to studying some written resources about this subject.

\section{Rice: a cause for settlement and selection of a place as a village}

The environment should have suitable soil, abundant water, and humid weather for rice growing. Jungle slopes and plains in Mazandaran with appropriate weather and water is an ideal place for rice production and for life. So, mountainous people moved to these places as soon as they learned how to farm. All social and cultural relationships, components and constituents, the context of villages and houses appeared to be related to rice-planting. 


\section{Rice and texture of village}

In fact, the context of villages is consisted of two main parts, rice field and residential area. These are affected by environmental and climatic factors. They are organized related to each other due to rice planting.

\subsection{Rice field texture}

There are two main water supplies, the river and Annoon(dam). In villages, these are two main structural factors for rice field's context in addition to bordering and Nefars.

\subsection{1 "Sar-oo" or river}

Water resources are important elements to shape the form of villages. Most rice planting villages are located beside large rivers as a main and natural source of water. Rice fields are formed along the primary or secondary river branches. This kind of water source is known as 'sar-oo'. Villages are located next to rice fields. The aspects of these villages are usually elongated due to easy access to rice fields which are spread beside the river, Fig. 1.

River and rice field of forestry villages which are topographic, usually are located in the lower side of the village. But in plain areas, rice lands completely surround residential areas, as shown in Fig. 1.

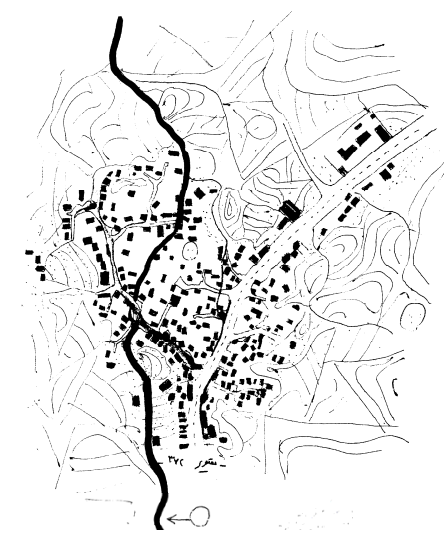

Figure 1: A village and the situation of three main elements: (residential context, rice field and river).

\subsubsection{Annoon (reservoir)}

Annons collect surface running water and rain water in autumn and winter agricultural seasons. The area and volume of these Annons depend on the area of lands which are required to be irrigated. On average, each Annon irrigates about 20-30 hectares of land. Because Annons are handmade, most of them are located outside the villages where are near to the agricultural lands. Usually they are about at least 500 meters far away from residential areas. Between these zones, they are free from any construction and devoted to playgrounds for youth. 


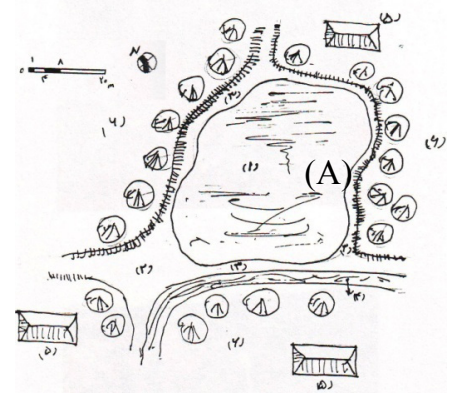

Figure 2: Annon inside the context of village [3]. (A-Annon and position of surrounding avenues, river, houses and gardens.)

But some Annons are rarely located in the middle of a village, Fig. 2. Of course, their volume and dimensions are small which create a very beautiful perspective for the residential part of villages.

Today, in addition to irrigation, these Annons are used as fish nourishment pools. Every village lends its own Annon and receives revenue for village development.

\subsubsection{Bordering}

Along with flourishing of the trees and nightingales songs in the fascinating season of spring, rice planters begin to prepare themselves for work.

Winter nights are good and spring days .... (Part of a folklore poem)

After New Year wishing for having a lucky year and simultaneously with interchange of visit, farmers start bordering. Flowing water is conveyed into a flat place. For this, land is bordered. These borders in fact, are contour lines of that land. It needs skillful experience to create border line in curvy shape and divide proper size for each pond. In addition, the exhaustive hard labor work is paid off by its pleasing aesthetic outcome, Fig. 3 .

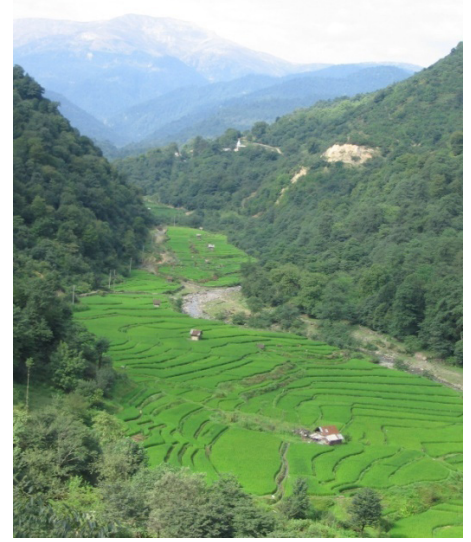

Figure 3: Beautiful perspective of a rice field in the heart of the jungle in spring. 
Rice fields formed by these very beautiful borders at the heart of the nature and magic jungle of Mazandaran present marvelous and attractive perspectives. Besides this picture, songs of hundreds of hidden toads and frogs make dreamful and unforgettable moments for any viewer, especially in spring.

\subsubsection{Nefar}

Rice can be endangered by pigs and boars at night time, and sparrows and other birds during the day. The responsibility of driving out sparrows and other birds from the farm during the day is not particularly hard work. Usually the youngest sons or even youngest girls will take care of the rice by spending their leisure times there during holidays. During the day, the father controls the amount of water flowing into the rice field, and also guards against other farmers robbing his share. He protects the rice field against pig and boar damage. He even spends all nights of the summer in Nefar. This custom of night protection for rice is called 'Shoupeh'.

.....Shoupeh is vigilant like a lover .... (A part of folklore poem)

A Nefar which is established inside the rice field is called Dashti-Nefar. Other kinds of Nefar are also established inside the house and beside the Tekiyeh (a kind of religious place), which are called 'kheneh-nefar'(house nefar) and 'Sagha-Nefar' respectively. Kheneh-nefar is in the porch of the houses and Sagha-nefar is a kind of mourning place. During the daytime, especially in the seedling and rice harvesting seasons, farmers rest in Dashti-Nefar, prepare daily food, have lunch and drink tea. They change their dirty clothes, wash their hands and feet in this place and go home clean. But if farmer's house is not far from rice field, Nefar is not established in the field. In this case, all of the activities for cleaning the body usually take place in the house yard.

Nefar is often a space which is completely open and there are no walls around it. It is usually built in two stories from the ground floor. The lower store level is an enclosed space and used as store or kitchen. The upper level is an open space and is used for resting and eating. The roof is mostly built as a gable roof (sloping roof) (Fig. 4). Dashti-Nefars are also built with wood like other kinds of Nefars, but they are built with a simpler technique and without any wooden decoration. It seems like a reasonable construction with simple

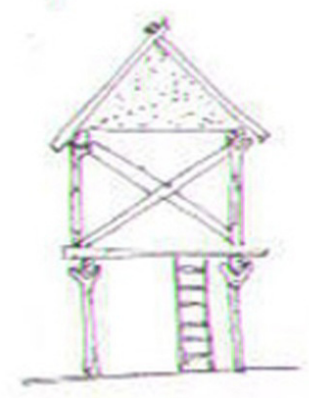

Figure 4: $\quad$ Sectional drawing of Dashti-Nefar [3]. 
technique for those Nefars that are only used for one or two years However house construction technique with better strength and durability is employed for those Nefars (khene-nefar and sagha-nefar) that are planned to use for a longer life time.

\section{Gathering ways of rice, basic steps toward architecture}

At the end of summer and beginning of the beautiful autumn is the fruitful harvesting season. Production of larger rice seeds and hay with the best quality for herds is very important. For this aim, the harvested rice should not be exposed to rain. Farmers have empirical knowledge for weather anticipation which is based on natural signs. To protect the rice against rain by storing it as some small buildings named "kouleh", "Bene-kar" and "dare-kar". It signifies the general form and appearance of tombs in Mazandaran that are very similar to general appearance of Bene-kar. The way to cover the roof of Ben-ekar and Dare-kar is also completely related to the idea of covering the roof of the buildings with rice hay. They are also constructed with steep roof. A narrow trench is dug surrounding the Beneh-kar for drainage which prevents water from flowing into Beneh-kar, Fig. 5. In Dare-kar, it is constructed with an elevated wooden platform in order to prevent water from getting into the storage area and reduce humidity, fig. 5. Perhaps, the idea of making a platform for the house would result from this.

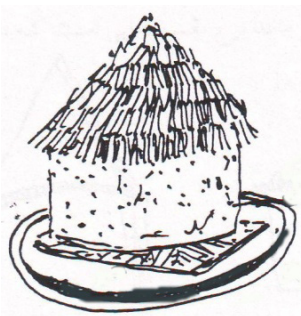

Bene-Kar

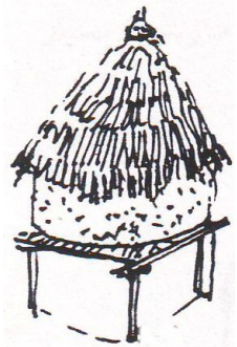

Dare-kar

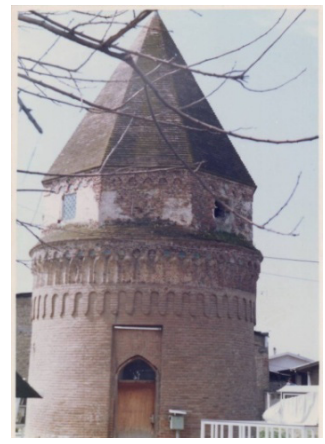

Figure 5: Tomb tower. 
Threshed rice or rice separated from its straw will be transported to factories to be husked. Usually, these factories are located inside the village or in the center of a village or beside the place of haunt for villagers which behave as haunt performance supplement, Fig. 6.

In the past, "Oudang" (a water wheel) was used in a kind of factory to bray and husk rice. It was famous in Mazandaran. Flowing water has been used as a power source to drive its blades in Oudang [1]. For this reason, all of them were placed beside the rivers, Fig. 7. Today, Oudags' buildings have been completely eradicated and these kinds of establishments are no longer found in Mazandaran.

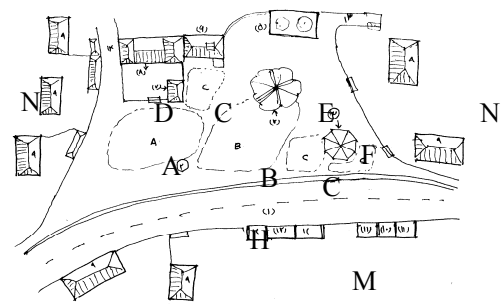

Figure 6: Haunt (neighborhood centre) of a village [3]. (A) Youth haunt B) play place for the youth C) old men haunt D) Religious complex E) Flail factory E) Old and big sacred tree F) Tomb tower H) Main street of village M) Local Shops N) Houses).

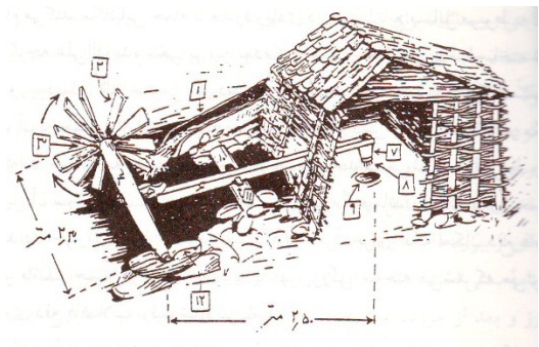

Figure 7: A picture of Oudang building [1].

\subsection{Residential texture}

Residential areas are always distinguished and separated from rice field areas. Although these two are completely dependent on each other but the edge of residential part is perfectly defined and these two are not blended into each other. It is always attempted to separate houses from rice fields due to the presence of mosquitoes, and other insects and animals, and humidity. However there is a main road and secondary passageway linking from the residential area to the heart of the rice field area. Some of them have the capacity just for the pedestrians and some others have the capacity for herds and agricultural machines. In fact, the largest part of village passages network is devoted to this kind of activity. 


\subsubsection{House}

If we look at the rural houses, work and life are mixed together. Houses in this region are settled in the relatively large area because of climatic reason. It allows to fully utilizing wind and solar powers like. The house is divided by different variety of activities. In a rice grower's house, it is divided by two main parts, front yard and back yard. Substantial activities, like the rice stalk store, poultry building, stable, orchard garden, vegetation, washing place and etc, are taking place around it. Houses are completely compatible with the climate. Most of them are built with local and natural materials like sod, mud, wood, and accessions of rice. Most houses are elongated along east-west axis to allow more surface areas facing south for solar heat. All rooms are adjacent to each other. Their doors open to semi-open space either in front of the house or other direction. This semi-open space is constructed with wooden columns and is the main space of the house. Besides it is the only space connecting directly to the front yard. It is emphasized to be a cultural and social place of the house.

5.2.1.1 Rice, house and customs. The autumn season, after the yield of harvesting, when the working season is just finish and leisure time begins. These leisure times are also used for recreational trips especially pilgrimage trips. Usually, wedding ceremonies are held during this season by putting a wedding veil in the house yard or rice field where they have been dried, Fig. 8. At the end of the wedding ceremony when the bride and groom together enter their house yard, rice is poured on their heads and bodies as a ritual symbol to protect them from bad spirits as well as a blessing. The main food of a wedding ceremony is also of rice like most days of the year. In addition to it, rice is also used as the original material to prepare different cookies for the feast and party. It is also used to decorate table cloths for the ceremony.
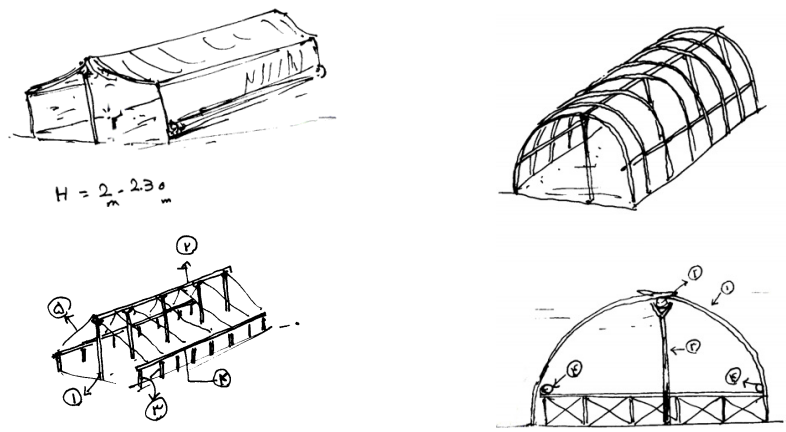

Figure 8: Two types of wedding ceremony tenant with wooden twigs [3].

After celebrations and wedding ceremonies, it is also the time for someone who wants to build a house. Because the fundamental building material for a house is wood, cutting trees is also suitable during winter. In any way, housing will be a good entertainment to fill up leisure times. During the days, if men have no work, they sit in neighborhood haunts beside the main square of the village, inside the store and tea shop talking about daily events. At night, they go to each 
other's house in early evening named "Shou-nisht". During Shou-nisht, most members of a family, man, woman, and child would participate. Shou-nisht is performed in 'kele-si-khene' where is the core space of a family. Men and women form their own groups and chat. Men sit at the upper part of the roomBala-kele-si- and beside a fireplace-kele-tash. It's the best place of the home. On the other hand, women sit in the lower part of the room-paien-kele-si- beside the kele and the entrance, Figs. 9 and 10.

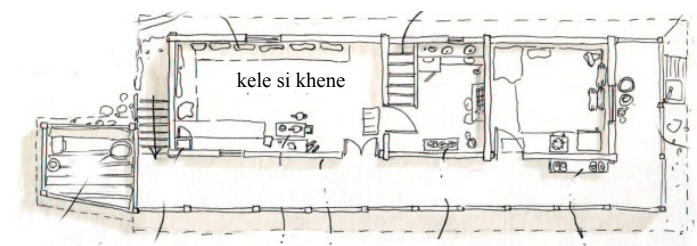

Figure 9: $\quad$ House and location of kele-si-khene [4].

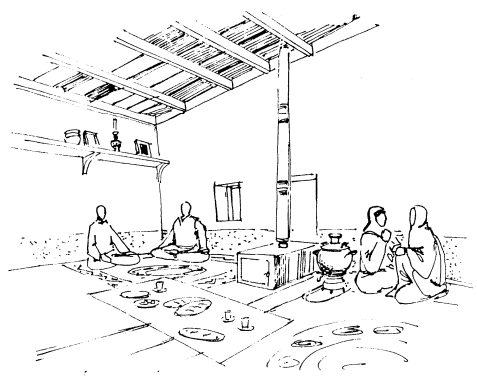

Figure 10: A perspective picture of kele-si-khene [3].

Kele-tash, a fireplace, not only provides heat for the family meeting to take place when it is cold but also a source to dry rice located under the gable roof.

Kele-si-khene is a multi-function space. Sometimes it serves as a guest room. It also serves as a main living space for rice planting people. In this place the wife cooks food for the family. Family members eat together and sleep at night. A quilt is available in this space which is usually covered by a very beautiful quilt cover that is made by the wife. It could be used as cushion during sitting periods. Nowadays, this space is equipped with home appliances, like a television and sometimes refrigerator. This space is rectangular-shaped and it has often east west elongation to exploit better sunlight. It provides a good orientation for wind coming from southern mountain during the night and northern sea during the day. Its length and width ranges from 3.5 to 5 meters and the 2.5-3.5 meter respectively. In fact, these dimensions are the most appropriate scale to establish friendly, close and eye-to-eye social relationship, Figs. 11 and 12 . 


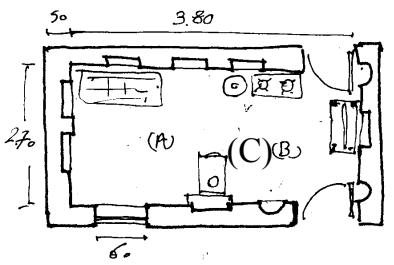

Figure 11: A picture of kele-si-khene [3]. A) Men zone; B) Women zone; C) fire place.

5.2.1.2 Rice and social stratification. Possessing more land for rice planting means more yields and more income. Those who have more income surely will have other income resources, such as a citrus garden, herd breeding and poultry. They can buy agricultural machines and devices for themselves to assist in their job with better efficiency. They could lend or hire them to others. Since they get more income, they could have a better location in the village and a bigger house. These houses provide more rooms and bigger yards. They can employ more skillful builders to construct their home. Sophisticated wooden decorative elements and better built wooden fences are easily found in these houses, Figs. 12, 13, and 14. Therefore, in this way, rice has created stratification among farmers society which has a direct relationship with the shapes of these homes. So, rice-planting has created three classes of homes with some differences and similarities.
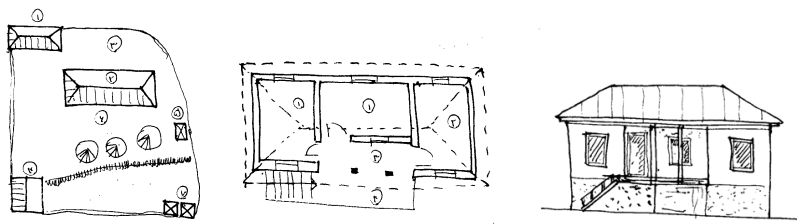

Figure 12: House of weak class of rice-planting people [3].
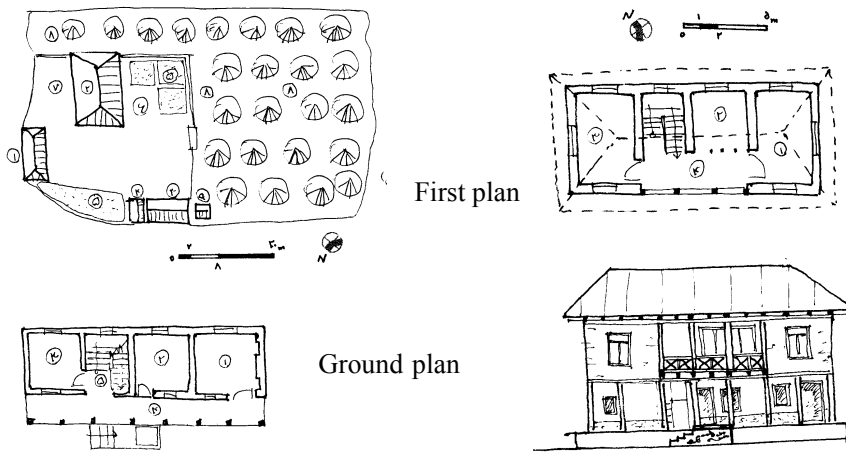

Ground plan

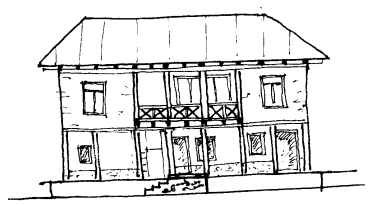

Figure 13: House belonging to middle class of rice-planting people [3]. 

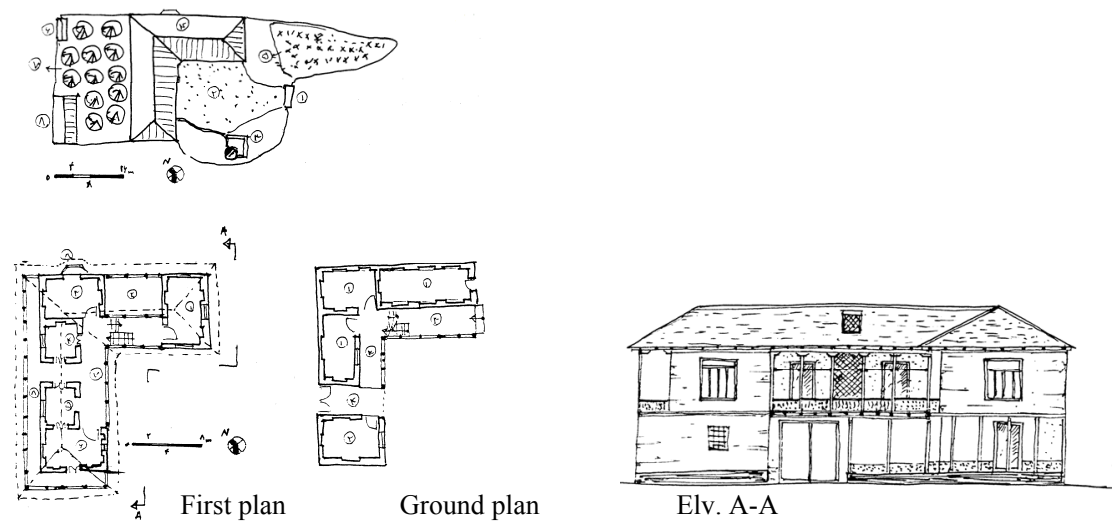

Figure 14: House belonging to rich classes of rice-planter people [3].

5.2.1.3 Rice and house construction. Different parts of rice, including the stalk and cluster are not powerful enough to be used as porter elements in house construction. But they can be used as natural available building materials for different purpose. In the past, for this reason, different parts of rice were used in building construction as plaster and roof coverage.

5.2.1.4 Rice for plaster. One of the important parts of rice that is used in building construction is plaster preparation and plastering. Rice skin and the rice straw are blended with different muds existing in the region, including white, black and yellow, to prevent plaster cracking. Different plasters are produced; "Gele-gouyi" is the most common one. Rice straw or skin is mixed with layers (stratum) to increase the layers and provide better resistance against stretching and cracking.

5.2.1.5 Rice for roof coverage. The most important, fundamental and known application of rice in house construction is to use rice stalk for final coverage of a steep roof, named Galeh. These kinds of houses are known as Galeh-be-sarkhene (house with Galeh cover). Galeh is not fastened to a wooden structure and because of that it can be damaged after severe wind and storms, otherwise it could cause leaking at the ceiling and make some problems. Moreover, a great part of Galeh would decay every year and it should be replaced. This was exhausting work for the house owner since it needed to be repaired by themselves or by a skillful specialist. Today tin and asbestos are used instead. During rain, a tin roof produces a huge noise. Asbestos cement is very heavy and requires a strong support. It costs more to build and makes the building heavier. And a roof with the common kind of asbestos in this region should not be high or too steep which can change the traditional proportion of the building façade. Also, it is carcinogenic. But Galeh is light and does not need a strong roof-truss to bear its weight. During rain it doesn't produce noise at all and one of the most important advantages of Galeh is its excellent insulation feature. 
5.2.1.6 Rice as decoration. Some farmers also make some furniture by using rice stalks along with its clusters. Besides, rice plant figures are engraved on wood decoration elements. Interestingly, sometimes a figure is being carved out and outlined at the void space between fences as a manifestation of top clusters, the shape of rice leaf and plant. It's like a reminder of a beautiful perspective of a rice field.

\section{Conclusions}

Rice has not only provided farmers in Mazandaran with an economical income but also a unique culture for the village community. Moreover, with its sanctity and different characteristics, this agricultural crop has drawn an integrated and consolidated life style along with architecture, especially housing. Besides, rural farmers do all of their work on their own by being helped from all of the family members and relatives to reduce cost expense. They have a routine and a definite plan for all seasons.

Today, due to insufficient income from planting rice, most farms are sold to outsiders. They change the farms into gardens, buildings and housing. This situation has weakened the integrated and unique culture established in the rice farmers' community. Rural inhabitants in this region essentially need to preserve traditional rice culture to cope with new lifestyles, but they still don't know how this important contradictory issue could be addressed. On one hand, they need to preserve traditional culture and architecture. On the other hand, the traditional one should be integrated with new standards of life and architecture. So, we should be eagerly studious in solving this problem which seems not to only to be in this region, but is a worldwide problem, especially in developing countries.

\section{References}

[1] Zargar, A., A prelude to Iran's rural architecture recognition, University of Shahid Beheshti: Tehran, 1999.

[2] Koulaeeyan, D. A., Sari and the beginning time of rice civilization, Shelflin publication: Sari, 2006.

[3] Yousefnia pasha, M., A survey on Bandpey rural architecture and society in design direction, Unpublished M.A. dissertation, College of Yazd Art and Architecture: 1380 .

[4] The projects of the students of university of Mazandaran's Art and Architecture College for village course (1), performed by following groups:A) Bagheri - Hassan zati - Javani, B) Manafi -Torabiyan -Majidi Ghassabiyan, C) Ghaem -Assari -Shiran, by supervision of Yousefnia pasha M., Mottaki M., and Seyyediyan A. 